\title{
Boxing Match Decisions as Influenced by the Practitioner Body Weight
}

\author{
André Mukala Nsengu Tshibangu \\ Department of Basic Sciences, Faculty of Pharmaceutical Sciences, University of Kinshasa, Kinshasa, Democratic Republic of the \\ Congo \\ Email: andrem36@hotmail.com
}

How to cite this paper: Mukala Nsengu Tshibangu, A. (2021) Boxing Match Decisions as Influenced by the Practitioner Body Weight. Open Access Library Journal, 8: e7159.

https://doi.org/10.4236/oalib.1107159

Received: January 19, 2021

Accepted: February 23, 2021

Published: February 26, 2021

Copyright (c) 2021 by author(s) and Open Access Library Inc.

This work is licensed under the Creative Commons Attribution International License (CC BY 4.0).

http://creativecommons.org/licenses/by/4.0/

\section{(c) (i) Open Access}

\begin{abstract}
In 99 of the top 100 male professional boxers enrolled in the present study, weight division midpoints are linked by 1) an average strength correlation with the number of non-knockout wins; 2) weak correlations with the number of all wins pooled together, the number of knockout wins as well as with the number of draws; and 3) strong correlations with the number of all losses pooled together, the number of knockout losses, as well as the number of non-knockout losses. Wins arithmetic mean values are lower than those of losses but higher than those of draws. Being weight division midpoints the independent variable, losses are linked with it with correlations stronger than those that link it with wins. Thus, 1) variables other than body weight could influence more the wins than the losses and 2) improving body weight could contribute less to increasing wins numbers than to decreasing losses numbers. As competition draws near, the selector must make sure that values shown by the weight as well as other variables (physical or non-physical) about each boxer are not far from values that could allow an ideal pugilistic performance. As average weight of boxers may vary with the passing time, the validity of conclusions drawn from the present study should be examined yearly within sight of possible necessary modifications.
\end{abstract}

\section{Subject Areas}

Mathematical Biology

\section{Keywords}

Anthropometry, Body Composition, Body Weight, Boxing, Martial Arts

\section{Introduction}

Boxing here concerned is a combat physical activity in which both practitioners 
opposed by each other use only his fists for landing light touches and/or hitting the opponent while avoiding the latter's fists reach his own legal targets. Light touches are concerned when, deliberately, the attacking boxer lands his fists on his opponent's legal targets without causing to the latter the least physical pain [1]. The legal targets comprise the anterior and lateral surfaces of the head, the neck and the trunk, above an imaginary plane passing through both iliac crests and parallel to the boxing ring. When, besides the fists use, that of other body parts (elbows, knees, legs and/or feet) is allowed as weapons, boxing is referred to, according to the case, Thai boxing, American boxing (full-contact) or French boxing.

Boxing may be described as recreational, educational, amateur or professional. In recreational boxing, competitions do not take place, contrary to educational, amateur and professional boxing. In educational boxing, hits are forbidden and replaced with light touches, contrary to amateur and professional boxing [1]. In amateur boxing, the practice is not carried out as a job: the boxer is not paid, contrary to the professional boxer.

In boxing, factors capable of influencing results obtainable by the practitioner may be of technical, tactical, psychological and/or physical natures. Anatomical (physical) factors permit the other three kinds of factors to contribute towards the results obtaining. Physical factors such as anthropometric (biometric) variable (weight, height, body surface area, ...) values are likely to influence athletes physical performance and may be useful when one would like to compare the performance of an athlete at different moments or to compare the performance of an athlete with that of other athletes [2].

Boxing Records Archives (BoxRec.com) internet database [3] provides, concerning both the retired and the active, male as well as female professional boxing practitioners, anthropometric data (body weight, stature ...), boxing match decisions and boxers ratings, among other things.

The mass of an object is defined as the amount of matter composing that object while the weight of the object is the product of its mass and the acceleration due to gravity $\left(\mathrm{g}=9.8 \mathrm{~m} / \mathrm{s}^{2}\right)$ [4]. The weight of an object is thus the force acting on that object due to gravity [4]. However, when a boxing practitioner is concerned, weight refers to the body mass and is described in terms of kilograms $(\mathrm{kg})$, a mass unit, instead of newtons $(\mathrm{N})$, a force unit.

The ordered array of weights shown by boxing practitioners may be divided into class intervals of non-equal width referred to as weight divisions (Table 1) [5]. In general, a boxer is not allowed to compete against another boxer belonging to a weight division different from his own.

A natural selection might exist and makes that successful practitioners in a given sport combine some specific qualities independently of any training [6].

In the case that body weight forms part of the specific qualities to which Vandervael alludes [6], correlation coefficients different from zero must link the weight of boxing practitioners enrolled in the present study with the decisions of boxing matches fought by the boxers. The present study is aimed to check that possibility. 
Table 1. Professional male boxers weight division ranges and midpoints [5].

\begin{tabular}{|c|c|c|c|c|}
\hline Weight Divisions & $\begin{array}{c}\text { Lower } \\
\text { Limits }(\mathrm{kg})\end{array}$ & $\begin{array}{c}\text { Upper } \\
\text { Limits (kg) }\end{array}$ & $\begin{array}{l}\text { Weight Division } \\
\text { Widths (kg) }\end{array}$ & $\begin{array}{c}\text { Weight Division } \\
\text { Midpoints (kg) }\end{array}$ \\
\hline Minimumweights & 46.267 & 47.627 & 1.36 & 46.947 \\
\hline Light Flyweights & 47.628 & 48.988 & 1.36 & 48.308 \\
\hline Flyweights & 48.989 & 50.802 & 1.813 & 49.8955 \\
\hline Super Flyweights & 50.803 & 52.163 & 1.36 & 51.483 \\
\hline Bantamweights & 52.164 & 53.525 & 1.361 & 52.8445 \\
\hline Super Bantamweights & 53.526 & 55.225 & 1.699 & 54.3755 \\
\hline Featherweights & 55.226 & 57.153 & 1.927 & 56.1895 \\
\hline Super Featherweights & 57.154 & 58.967 & 1.813 & 58.0605 \\
\hline Lightweights & 58.968 & 61.235 & 2.267 & 60.1015 \\
\hline Super Lightweights & 61.236 & 63.503 & 2.267 & 62.3695 \\
\hline Welterweights & 63.504 & 66.678 & 3.174 & 65.091 \\
\hline Super Welterweights & 66.679 & 69.85 & 3.171 & 68.2645 \\
\hline Middleweights & 69.851 & 72.574 & 2.723 & 71.2125 \\
\hline Super Middleweights & 72.575 & 76.203 & 3.628 & 74.389 \\
\hline Light Heavyweights & 76.204 & 79.378 & 3.174 & 77.791 \\
\hline Cruiserweights & 79.379 & 90.892 & 11.513 & 85.1355 \\
\hline Heavyweights & 90.893 & 102.406 & 11.513 & 96.6495 \\
\hline
\end{tabular}

\section{Material and Methods}

Boxing Records Archive (BoxRec.com), the web-based database, retrieved anthropometric data on the sportspersons enrolled in the present study. The latter are the Democratic Republic of the Congo top 100 male professional boxers, BoxRec.com ranked, and retired in the period lasting from beginning of professional boxing practice to March $8^{\text {th }}, 2010$ [3].

Ratings as well as belonging to professional weight divisions have been signaled for all the boxers excepting for the boxer 92 whose date of birth, victories, losses and draws have not been shown. For that, in the results and discussion appearing below, one is going to read " 99 of the top 100 professional boxers" instead of "the top 100 professional boxers".

Microsoft Office Excel 2007 has been used for both descriptive and inferential statistics: recording data gathered from internet, data selection, arithmetic means and standard deviations computations, tables edition, figures drawing, plotting scatter diagrams with the purpose of concluding in the existence or the non-existence of relationships between sets of data pairs (body weight on the one hand, and on the other hand different boxing match decisions), as well as 
correlation coefficients computation.

Although this is sometimes impossible, class intervals generally should be of the same width [7]. It has been found important to remind that boxer weight divisions are classes which show exceptional widths: those classes show a trend to increase from lighter weight divisions to heavier weight divisions (Table 1). In the database consulted, boxer weights are replaced with the name of the weight division to which belong the boxers. Nevertheless, division limits are signaled, what permitted to compute the middle of each class interval, here being the mean of each weight division limits. Each class midpoint has been calculated by adding the class inferior limit to the class superior limit and by dividing next the result by two. It is worth signaling that both extreme weight divisions have only one limit: upper limit for the minimum weights division and lower limit for the heavyweights division. Nonetheless, with the aim of facilitating certain operations, lacking limits have been arbitrarily set by giving to each extreme weight division the same width as that of the division nearest to it. That is the reason why the reader is going to see hereafter the computed midpoint value of the minimum weights $(46.947 \mathrm{~kg}$ ) and the computed midpoint value of the heavyweights $(96.6495 \mathrm{~kg}$ ) divisions, while those midpoints do not actually exist.

\section{Results}

\subsection{Relationships between Body Weight and Other Variables in the 99 of the Top 100 Professional Boxers}

In 99 of the top 100 Democratic Republic of the Congo male professional boxers retired on March $8^{\text {th }}, 2010$ (Table 2), weak correlations $(r=0.49, r=0.4$ and $r=$ 0.46 respectively) link weight division midpoints with all victories pooled together, with $\mathrm{KO}$ victories as well as with draws. An average strength correlation $(\mathrm{r}=0.5)$ links weight division midpoints with non-KO victories. Strong correlations ( $r=0.68, r=0.76$ and $r=0.7$ respectively) link weight division midpoints with losses (all pooled together, KO losses considered separately and non-KO losses considered separately).

Table 2. Trend lines of relationships between body weight and other variables in 99 of the top 100 professional boxers.

\begin{tabular}{ccc}
\hline Boxers weight division midpoints & Trend lines equations & Correlation coefficients $(\mathrm{r}=)$ \\
\hline All victories pooled together & $\mathrm{y}=-0.003 \mathrm{x}^{2}+0.610 \mathrm{x}-18.42$ & 0.49 \\
KO victories & $\mathrm{y}=-0.000 \mathrm{x}^{2}+0.153 \mathrm{x}-4.621$ & 0.4 \\
Non-KO victories & $\mathrm{y}=-0.002 \mathrm{x}^{2}+0.457 \mathrm{x}-13.80$ & 0.5 \\
Draws & $\mathrm{y}=-0.001 \mathrm{x}^{2}+0.229 \mathrm{x}-7.098$ & 0.46 \\
All losses pooled together & $\mathrm{y}=-0.008 \mathrm{x}^{2}+1.374 \mathrm{x}-43.93$ & 0.68 \\
KO losses & $\mathrm{y}=0.000 \mathrm{x}^{2}+0.018 \mathrm{x}-0.589$ & 0.76 \\
Non-KO losses & $\mathrm{y}=-0.009 \mathrm{x}^{2}+1.356 \mathrm{x}-43.34$ & 0.7
\end{tabular}




\subsection{All Victories Pooled Together Mean Values as a Function of Weight Division Midpoints}

The polynomial trend line shows an average strength link $(\mathrm{r}=0.49)$ between both variables (Figure 1). With increasing weight division midpoint values, the line shows an increase in all victory numbers to a maximal value before a subsequent decrease. Computing the parabola vertex yields the point that could correspond to the largest number of victories, the point corresponding to 101.667 $\mathrm{kg}$, a weight that falls into the weight range of professional heavyweight boxers.

In the population concerned with the present study, all victories pooled together numbers mean value is 5.1, with a standard deviation of 2.9.

\subsection{KO Victories Mean Values as a Function of Weight Division Midpoints}

The polynomial trend line shows an average strength link $(\mathrm{r}=0.4)$ between both variables (Figure 2). With increasing weight division midpoints values, the line shows an increase in $\mathrm{KO}$ victory numbers. Computing the parabola vertex yields the point that could correspond to the largest number of KO victories, the point corresponding to $+\infty \mathrm{kg}$, a weight that falls into the actual range of the professional heavyweight boxers.

In the population concerned with the present study, $\mathrm{KO}$ victory numbers mean value is 2 , with a standard deviation of 1.5 .

\subsection{Non-KO Victories Mean Values as a Function of Weight Division Midpoints}

The polynomial trend line shows an average strength link $(\mathrm{r}=0.5)$ between both variables (Figure 3 ). With increasing weight division midpoint values, the line shows an increase in non-KO victory numbers to a maximal value before a subsequent decrease. Computing the parabola vertex yields the point that could correspond to the largest number of non-KO victories, the point corresponding to $114.25 \mathrm{~kg}$, a weight that falls into the weight range of the professional heavyweight boxers.

In the population concerned with the present study, non-KO victory numbers mean value is 3.1 , with a standard deviation of 1.7.

\subsection{Draws Mean Values as a Function of Weight Division Midpoints}

The polynomial trend line shows an average strength link $(r=0.46)$ between both variables (Figure 4). With increasing weight division midpoint values, the line shows an increase in draws numbers to a maximum value before a subsequent decrease. Computing the parabola vertex yields the point that could correspond to the largest number of draws, the point corresponding to $114.5 \mathrm{~kg}$, a weight that falls into the weight range of the professional heavyweight boxers.

In the population concerned with the present study, draws numbers mean value is 1.2 , with a standard deviation of 0.8 . 

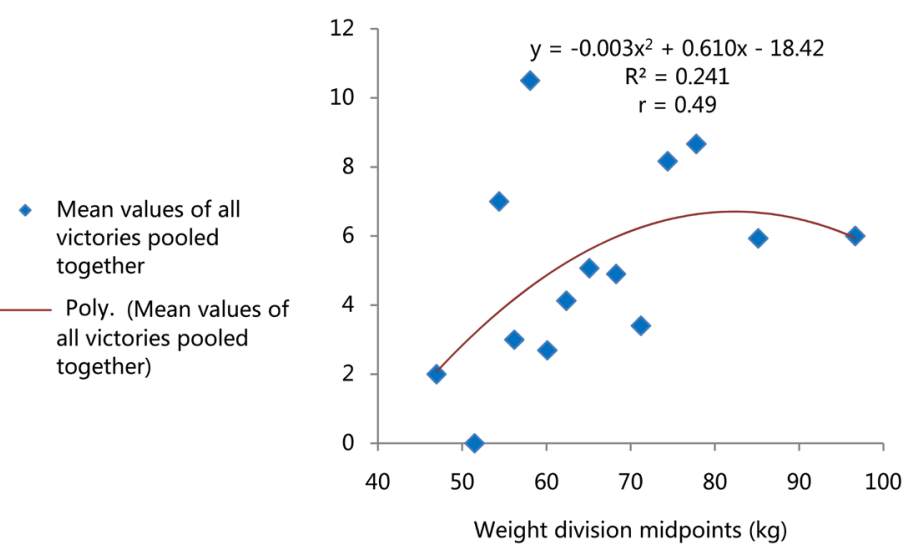

Figure 1. All victories pooled together mean values as a function of weight division midpoints. The polynomial trend line shows an average strength link $(r=0.49)$ between both variables. With increasing weight division midpoint values, the line shows an increase in all victory numbers to a maximal value before a subsequent decrease.

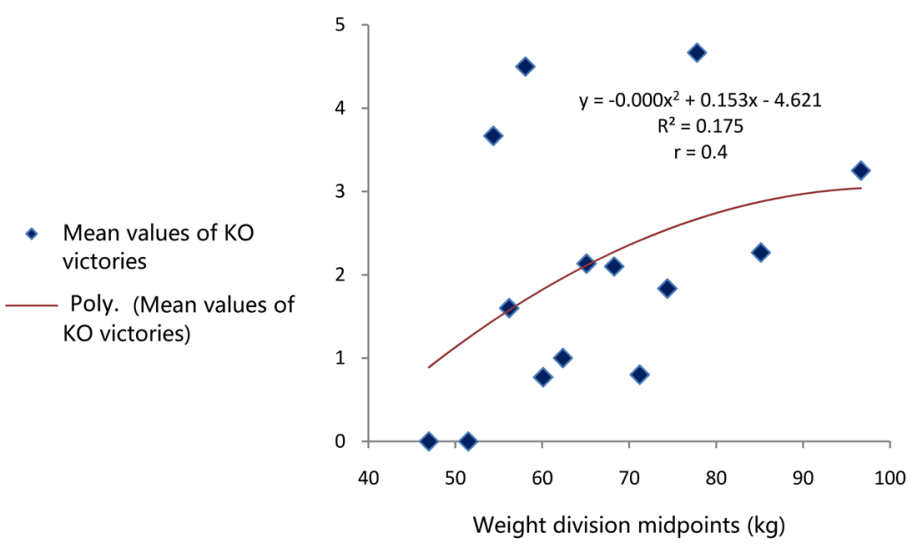

Figure 2. KO victory mean values as a function of weight division midpoints. The polynomial trend line shows an average strength link $(\mathrm{r}=0.4)$ between both variables. With increasing weight division midpoints values, the line shows an increase in $\mathrm{KO}$ victory numbers.

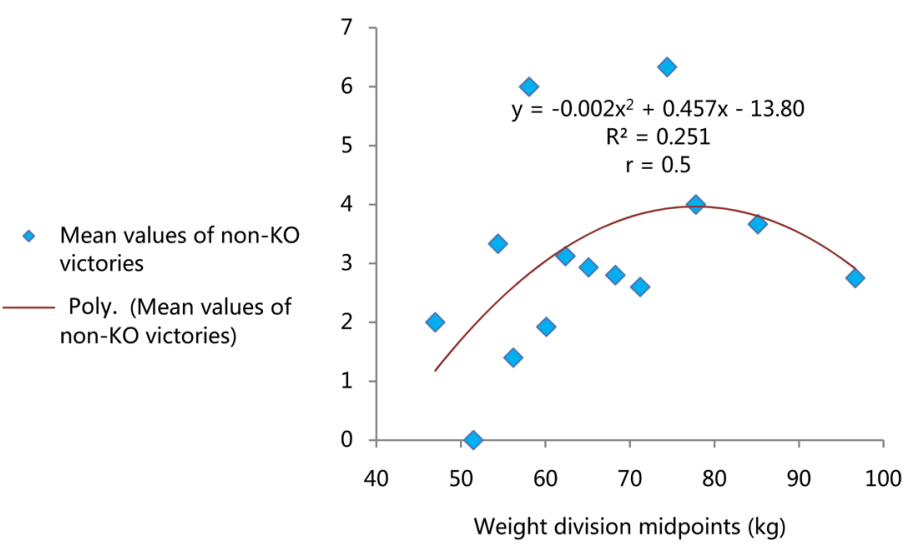

Figure 3. Non-KO victories mean values as a function of weight division midpoints. The polynomial trend line shows an average strength link $(r=0.5)$ between both variables. With increasing weight division midpoint values, the line shows an increase in non-KO victory numbers to a maximal value before a subsequent decrease. 


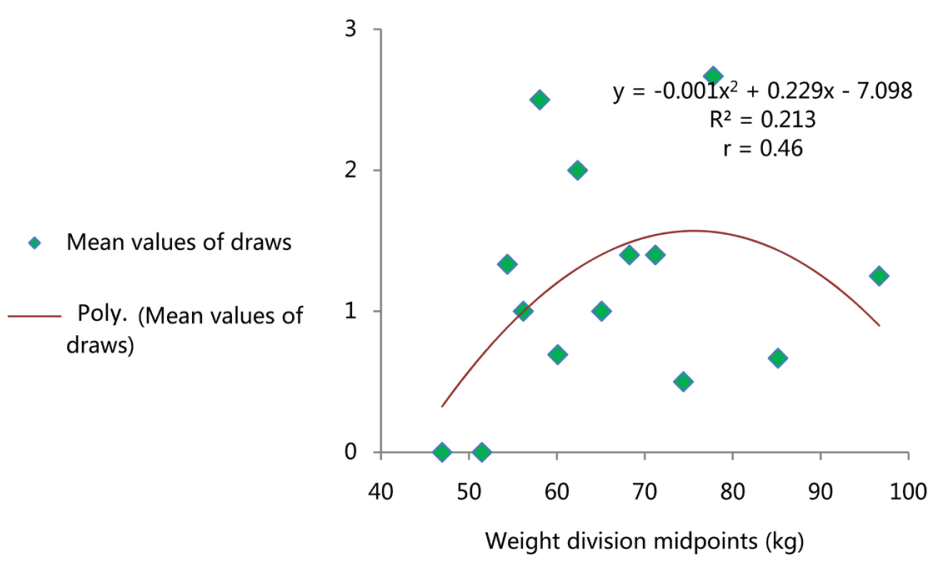

Figure 4. Draws mean values as a function of weight division midpoints. The polynomial trend line shows an average strength link $(r=0.46)$ between both variables. With increasing weight division midpoint values, the line shows an increase in draws numbers to a maximum value before a subsequent decrease.

\subsection{All Losses Pooled Together Mean Values as a Function of Weight Division Midpoints}

The polynomial trend line shows a strong link $(\mathrm{r}=0.68)$ between both variables (Figure 5). With increasing weight division midpoint values, the line shows an increase in all losses numbers to a maximum before a subsequent decrease. Computing the parabola vertex yields the point that could correspond both to the largest number of losses and $85.875 \mathrm{~kg}$, a weight that falls into the weight range of cruiserweight professional boxers.

In the population concerned with the present study, all losses pooled together numbers mean value is 6.8 , with a standard deviation of 3.7 .

\subsection{KO Losses Mean Values as a Function of Weight Division Midpoints}

The polynomial trend line shows a strong link $(r=0.76)$ between both variables (Figure 6). With increasing weight division midpoint values, the line shows an increase in KO losses number. The point that could correspond to the largest number of KO losses corresponds to $+\infty \mathrm{kg}$, a weight that falls into the actual range of professional heavyweight boxers.

In the population concerned with the present study, $\mathrm{KO}$ losses numbers mean value is 2.2 , with a standard deviation of 1.2 .

\subsection{Non-KO Losses Mean Values as a Function of Weight Division Midpoints}

The polynomial trend line shows a strong link $(r=0.7)$ between both variables (Figure 7). With increasing weight division midpoint values, the line shows an increase in non-KO losses to a maximal value before a subsequent decrease. Computing the parabola vertex yields the point that could correspond to the largest number of non-KO losses, the point corresponding to $75.333 \mathrm{~kg}$, a weight that falls into the range of the super middleweight male professional boxers. 


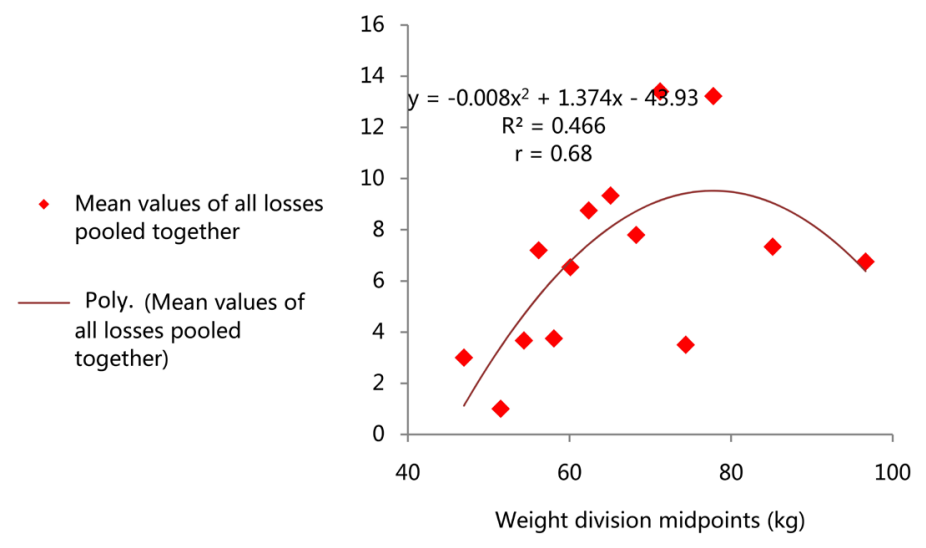

Figure 5. All losses pooled together mean values as a function of weight division midpoints. The polynomial trend line shows a strong link $(r=0.68)$ between both variables. With increasing weight division midpoint values, the line shows an increase in all losses numbers to a maximal value before a subsequent decrease.

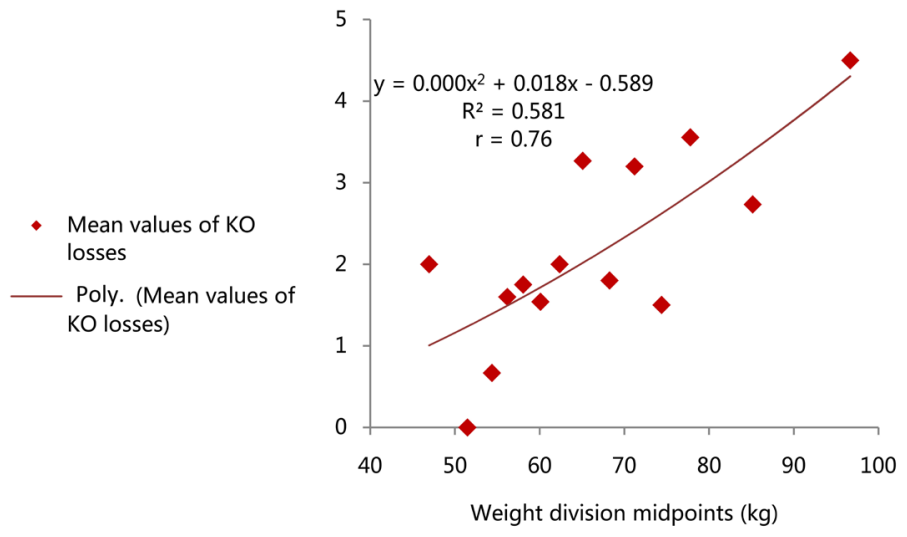

Figure 6. KO losses mean values as a function of weight division midpoints. The polynomial trend line shows a strong link $(r=0.76)$ between both variables. With increasing weight division midpoint values, the line shows an increase in $\mathrm{KO}$ losses number.

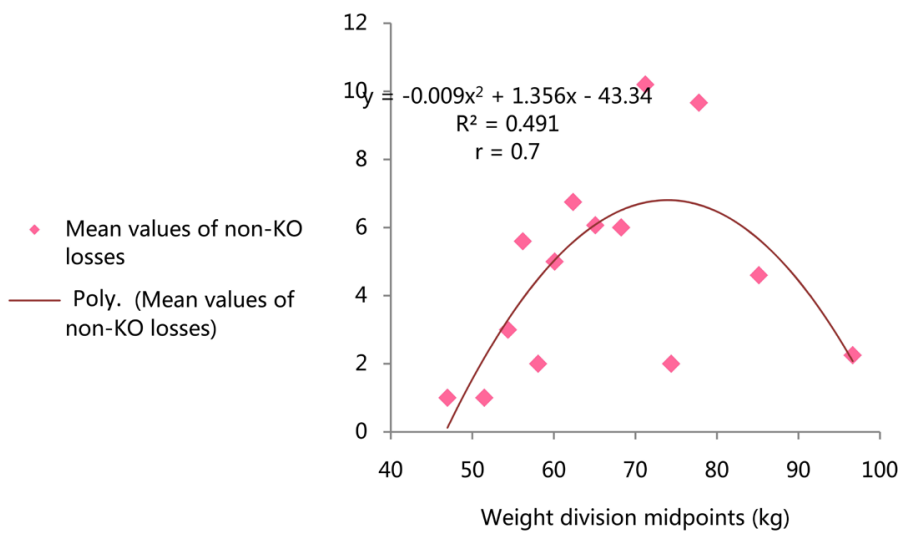

Figure 7. Non-KO losses mean values as a function of weight division midpoints. The polynomial trend line shows a strong link $(r=0.7)$ between both variables. With increasing weight division midpoint values, the line shows an increase in non-KO losses to a maximal value before a subsequent decrease. 
In the population concerned with the present study, non-KO losses numbers mean value is 4.7 , with a standard deviation of 3 .

\section{Discussion}

\subsection{Correlation Coefficients}

Weak correlations ( $\mathrm{r}=0.49, \mathrm{r}=0.4$ and $\mathrm{r}=0.46$ respectively) link weight division midpoints with all victories pooled together, with $\mathrm{KO}$ victories as well as with draws (Table 2, Figure 1, Figure 2 and Figure 4). Consequently, apart from other sources, weight division midpoints contribute only weakly as one source of the total variation present in the victories and draws obtained by the boxers.

An average strength correlation $(\mathrm{r}=0.5)$ links weight division midpoints with non-KO victories (Table 2 and Figure 3). Therefore, all alone, weight division midpoints contribute as a source of variation up to $50 \%$ towards the total variation present in the non- $\mathrm{KO}$ victories won by the boxers.

Strong correlations $(r=0.68, r=0.76$ and $r=0.7$ respectively) link weight division midpoints with losses [all losses pooled together, $\mathrm{KO}$ losses considered separately and non-KO losses considered separately (Table 2, Figures 5-7)]. Weight division midpoints of boxers enrolled in the present study could contribute a great deal towards the total variation present in the losses suffered by the boxers.

\subsection{Vertexes of Trend Lines}

Table 2 signals trend lines shown by certain variables according to weight division midpoints of the boxers enrolled in the present study.

Most of those lines are parabolas which vertexes may be either maximum or minimum values. However, when $\mathrm{KO}$ victories are concerned (Figure 2), the vertex (maximum value) approaches infinity, in other words, with increasing boxer's weight, the boxer's chance of KO victory increases. When KO losses are concerned (Figure 6), the vertex (minimum value) approaches infinity, in other words, with decreasing boxer's weight, the boxer's possibility to suffer a KO loss only decreases. In fact, 1) two opposing boxers generally belong to the same weight division; and as afore signaled, 2) the maximum weight value should increase the chance to knock out the opponent, while 3) the minimum weight value should decrease the possibility to be knocked out by the opponent of the same weight division (the division in which the chance to $\mathrm{KO}$ is the least).

Vertexes and trend lines mentioned in Table 1 have been computed and show that when weight is the independent variable, 1) the largest number of victories (all pooled together) could be won by heavyweight boxers (101.667 kg), 2) the largest KO victory number could be won by the heavyweight boxers $(+\infty \mathrm{kg}), 3)$ the largest non-KO victory number could be won by heavyweight boxers (114.25 $\mathrm{kg})$, 4) the largest number of draws could be obtained by heavyweight boxers $(114.5 \mathrm{~kg}), 5)$ the largest number of losses (all pooled together) could be suffered 
by cruiserweight boxers $(85.875 \mathrm{~kg}), 6)$ the largest number of $\mathrm{KO}$ losses could be suffered by heavyweight boxers $(+\infty \mathrm{kg})$, and 7) the largest number of non-KO losses could be suffered by super middleweight boxers $(75.333 \mathrm{~kg})$.

\subsection{Distribution of 99 of the Top 100 Professional Boxers in Their Respective Weight Divisions}

Respectively, Figures 1-3 show that when the independent variable is the weight division midpoints, the 99 boxers concerned with the present study are distributed more in weight divisions lighter than in weight divisions heavier than the maximum values of the trend lines $(111.667 \mathrm{~kg},+\infty \mathrm{kg}$ and $114.25 \mathrm{~kg}$ respectively).

Therefore, most of the 99 boxers show values smaller than maximal values the trend lines let expect when victories (all pooled together, $\mathrm{KO}$ victories considered separately and non-KO victories considered separately) are concerned.

For most of the concerned boxers, pugilistic practice could have been too dangerous and/or too overtaxing. Too dangerous, the practice could have obliged boxers to practice in weight divisions where closed fists landed by the opponents could be easily withstood, in other words, in weight divisions which are far from divisions where KO losses numbers are small (Figure 6). Too overtaxing, the boxers here concerned could be endowed only slightly with anatomical, physiological and/or psychological variables which are useful for an optimal pugilistic performance.

The possible existence of a permanent underweight situation in Democratic Republic of the Congo could support the fact that the presence of concerned boxers is more noticeable in divisions lighter than light heavyweight, cruiserweight and heavyweight divisions [8].

\subsection{All Victories Pooled Together Mean Values as a Function of Weight Division Midpoints}

People tend to engage in physical activities which are the less overtaxing for them [6]. As boxing work velocity decreases with increasing weight division midpoint, heavier boxers are expected to move sparingly and to be prone to land hard their closed fists on legal targets whenever the latter are defenseless. Heavier boxers closed fists are thus expected to produce a force of impact greater than the force of impact produced by lighter boxers. As the case may be, it may be due to the possession by heavier boxers of larger corresponding muscles or of larger muscle cross-sectional areas compared to those of the lighter boxers. That possibly results in the greater possibility of heavier boxers to KO their opponents. The possibility to win by knocking out the opponent increases thus with increasing body weight. It could even increase indefinitely: KO victories trend line (Figure 2) has its maximum in the infinity.

Both non-KO victories trend line (Figure 3 ) and all victories pooled together trend line (Figure 1), as functions of weight division midpoints, have a maximum. That supports any opinion according to which there could exist an ideal 
body weight that favors boxing activity, even in the population made of boxers enrolled in the present study. Showing a lighter or a heavier body weight could thus turn pugilistic work more overtaxing than when showing the ideal body weight. As a matter of fact, in the lighter boxers, where victories require less maximal force use than totaling the larger number of successful closed fists landing, mobility becomes essential during the attacks as well as during the defenses. That results in the decrease of non-KO victory numbers when body weight turns heavier than the trend line maximum (Figure 3). Progressive increase in victory numbers with increasing body weight below the maximum number could result from the advantages related to the boxers weight increase.

Learning and/or creation of attack techniques and tactics as well as of defense techniques and tactics may vary from one boxer to another and thus may contribute as one source of variation in the victories won by the boxers. An additional contribution may derive from the boxer's facility for controlling his own emotions or for causing his opponent lose self-control.

The correlation that links victories to weight division midpoints of the boxers enrolled in the present study (Table 2) let foresee 1) possible technical, tactical and/or psychological weaknesses that forbid the boxers from fully take advantage of their physical talent (here, their respective body weights), as well as 2) the possibility to intervene within sight of increasing victory numbers (intervention from the physical, technical, tactical and/or psychological standpoints).

\subsection{Draws Mean Values as a Function of Weight Division Midpoints}

Professional boxing is carried out as a job: the practitioners are paid. The boxers are thus expected to fight merciless so as to defeat the opponent and in that way to be sure to have a good professional future: they are expected to avoid a loss as well as a draw. Nonetheless, when a boxer suffers a loss (a boxing decision different from a draw), that amounts to a victory won by his opponent, a boxer belonging to the same weight division as his own. There is hence only little room left for draws when compared with victory and loss numbers. That is witnessed by the result of comparison between the trend line and ordinate axis uppermost values in Figure 4 (draws) on the one hand and on the other hand trend line vertexes and ordinate axis uppermost values in Figure 2, Figure 3, Figure 6 and Figure 7 (KO victories, non-KO victories, $\mathrm{KO}$ losses and non-KO losses respectively).

\subsection{All Losses Pooled Together as a Function of Weight Division Midpoints}

The number of KO losses (Figure 6) increases with boxers increasing weight division midpoints. The related trend line is curved downwards. There is thus increase in sensitivity to KO-producing fists with increasing boxer weight division midpoints. 
Parabolas representing trend lines show maximal values when all losses pooled together (Figure 5) and non-KO losses (Figure 7) are concerned. The decrease in non-KO losses suffered by boxers heavier than the trend line maximum values suggests an increase in the possibility of suffering $\mathrm{KO}$ losses with increasing weight division midpoints as afore signaled and, thus, a decrease in the possibility of suffering non-KO losses.

The increase in non-KO losses showed by boxers lighter than the trend lines maximum values could be related to the fact that in the concerned weight range, both career lengths and all boxing matches fought numbers increase with weight division midpoints [9].

\subsection{Victories versus Losses}

Figure 1 and Figure 5 evidence that in the boxers enrolled in the present study, all victories pooled together numbers are smaller than all losses pooled together numbers. Compare to that effect in both figures the respective trend line maximums and ordinate axis maximums. Note also the increasing mean values numbers (Figure 8 ) in the following sequence: draws $<\mathrm{KO}$ victories $<\mathrm{KO}$ losses $<$ non-KO victories $<$ non-KO losses $<$ all victories pooled together $<$ all losses pooled together. It is noticeable that in the boxers enrolled in the present study, 1) there has been very little room for draws; 2 ) there have been more losses than victories a) when $\mathrm{KO}$ decisions have been taken, b) when non-KO decisions have been taken, and c) when both $\mathrm{KO}$ and non- $\mathrm{KO}$ decisions have been pooled together.

Being weight division midpoints the independent variable, losses are here linked with it with correlations stronger than those that link it with wins (Table 1). Hence, weights of the boxers here concerned contribute as one source of the total variation present more in the losses than in the victories numbers: variables other than body weight could influence more the victories than the losses. Those variables could be of physical, technical, tactical and/or even psychological natures.

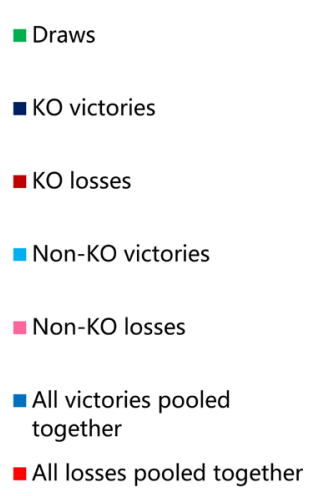

All losses pooled together
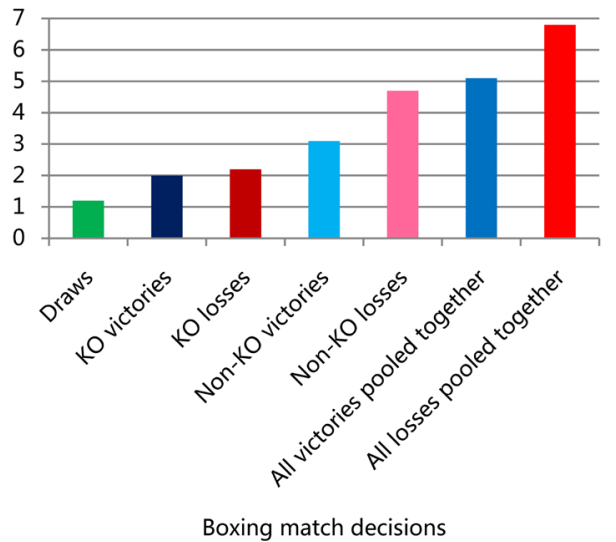

Figure 8. Boxing match decisions mean values of numbers. In each case, wins arithmetic mean values are lower than those of losses but higher than those of draws. 


\section{Conclusions}

In the population constituted by the professional male boxers enrolled in the present study, weight division midpoints are linked by 1) an average strength correlation with the number of non-KO wins; 2) weak correlations with the number of all wins pooled together, the number of $\mathrm{KO}$ wins as well as the number of draws; and 3) strong correlations with the number of all losses pooled together, the number of $\mathrm{KO}$ losses considered separately, as well as the number of non-KO losses considered separately.

As average weight of boxers may vary with the passing time [9], the validity of conclusions drawn from the present study should be examined yearly within sight of possible necessary modifications.

\section{Advice to the Selector for Competitions}

As competition draws near, the selector must make sure that values shown by the weight as well as other variables (physical or non-physical) about each boxer are not far from values that could allow an ideal pugilistic performance.

\section{Acknowledgements}

The author of the present study expresses his gratitude to BoxRec.com, the web-based database from which have been gathered data on the subjects enrolled in the study.

\section{Conflicts of Interest}

The author declares no conflicts of interest regarding the publication of this paper.

\section{References}

[1] Mukala Nsengu Tshibangu, A. (2013) Educational Boxing Is Worth Becoming a Template for Building up Concussion Prevention Means in Children and Adolescents Sports. Advances in Physical Education, 3, 50-52.

https://doi.org/10.4236/ape.2013.31008

[2] Fédération Française de Boxe (2005) Règlement Boxe Éducative Assaut BEA, Fédération Française de Boxe, Pantin.

[3] BoxRec.com (2010) BoxRec Boxing Records. http://boxrec.com/

[4] Karduna, A.R. (2009) Introduction to Biomechanical Analysis. In: Oatis, C.A., Ed., Kinesiology: The Mechanics \& Pathomechanics of Human Movement, 2nd Edition, Lippincott Williams \& Wilkins, Philadelphia, PA, 3-20.

[5] BoxRec.com (2010) Current Weight Divisions, BoxRec Boxing Encyclopaedia. http://boxrec.com/media/index.php/Weight divisions.

[6] Vandervael, F. (1943) Biométrie Humaine. Desoer, Liège.

[7] Daniel, W.W. (1987) Biostatistics: A Foundation for Analysis in the Health Sciences. 4th Edition, John Wiley \& Sons, Inc., New York.

[8] Mukala Nsengu Tshibangu, A. (2017) Health Concerns and Talented Sportspersons Identification Derivable from Height, Weight, Body Mass Index and Ectomorphy 
Rating Mean Values in Democratic Republic of the Congo (DRC) 2016-2017. Open Access Library Journal, 4, e3915. https://doi.org/10.4236/oalib.1103915

[9] Mukala Nsengu Tshibangu, A. (2020) Corrélations entre Poids et Durées de Carrière, Nombre de Combats, Mérites Pugilistiques, Années de Naissance des Boxeurs Professionnels RD-Congolais Retirés. Congo Sciences, 8, 89-99. 